\title{
Vinorelbine as substitute for vincristine in patients with diffuse large B cell lymphoma and vincristine-induced neuropathy
}

\author{
Stefan Hatzl ${ }^{1}$ (D) - Florian Posch ${ }^{2} \cdot$ Arwin Rezai $^{3}$ - Maximilian Gornicec ${ }^{1} \cdot$ Christine Beham-Schmid $^{4} \cdot$ Theresa Magnes $^{3}$. \\ Sandro Wangner ${ }^{3}$ - Alexander Deutsch ${ }^{1}$. Hildegard Greinix ${ }^{1}$ - Barbara Uhl ${ }^{1} \cdot$ Katharina T. Prochazka ${ }^{1}$. \\ Alexander Egle $^{3} \cdot$ Richard Greil $^{3} \cdot$ Thomas Melchardt $^{3} \cdot$ Werner Linkesch $^{1} \cdot$ Eduard Schulz $^{1} \cdot$ Peter Neumeister $^{1}$
}

Received: 15 October 2020 / Accepted: 7 February 2021 / Published online: 24 February 2021

(C) The Author(s) 2021

\begin{abstract}
Background A combination of rituximab with cyclophosphamide, doxorubicin, vincristine, and prednisone (R-CHOP) is the standard first-line therapy for diffuse large B cell lymphoma (DLBCL), the most common aggressive lymphoma in adults. One of the major adverse effects of this regimen is vincristine-induced polyneuropathy which leads to discontinuation of vincristine in up to $30 \%$ of DLBCL-patients. Dose reduction of vincristine might worsen treatment outcomes of DLBCL but identification of treatment alternatives for patients exhibiting peripheral neuropathy during R-CHOP is an unmet need in hematology.

Methods In this retrospective cohort study, comprising 987 patients with de novo DLBCL, we delineated the role of vinorelbine as a substitute for vincristine in R-CHOP by measuring improvements in neuropathy and outcome variables.

Results Five-year overall survival (OS) and progression-free survival (PFS) were $72.6 \%$ and $63.1 \%$ in patients who received regular doses of vincristine, as compared to $60.6 \%$ and $51.7 \%$ in patients who received reduced doses of vincristine $(p=0.022$ and $p=0.003$, respectively). Of 199 patients who switched to vinorelbine, the majority experienced an improvement of neuropathy Furthermore, vinorelbine-switched patients showed favorable oncologic outcomes.

Conclusion Replacement of vincristine by vinorelbine due to neuropathy is effective and safe, and results in a significant improvement in neuropathy as compared to treatment with R-CHOP.
\end{abstract}

Keywords Vino-R-CAP · Peripheral neuropathy · DLBCL · R-CHOP · Vinorelbine

Prof. Dr. Werner Linkesch passed away on December 9, 2018

Previous presentations This study has not been presented before this submission

\section{Stefan Hatzl}

stefan.hatzl@medunigraz.at

Peter Neumeister

peter.neumeister@medunigraz.at

1 Division of Hematology, Department of Internal Medicine, Medical University of Graz, Graz, Austria

2 Division of Oncology, Department of Internal Medicine, Medical University of Graz, Graz, Austria

3 Laboratory for Immunological and Molecular Cancer Research, Oncologic Centre, 3rd Medical Department with Hematology and Medical Oncology, Hemostaseology, Rheumatology and Infectious Diseases, Paracelsus Medical University Salzburg, Salzburg, Austria

4 Institute of Pathology, Medical University of Graz, Graz, Austria

\section{Introduction}

Diffuse large B cell lymphoma (DLBCL) is the most common aggressive non-Hodgkin lymphoma (NHL) in adults accounting for more than $30 \%$ of all NHL cases [1, 2]. Vincristine, a microtubule assembly inhibitor, has become an integral component of today's treatment of DLBCL since its discovery as an active agent against lymphoma. A combination of vincristine with cyclophosphamide, hydroxydaunorubicin, prednisone, and the monoclonal antibody rituximab (R-CHOP) administered in 21-day intervals is the standard of care and results in 5-year overall survival (OS) rates of up to $87 \%$ depending on risk factors $[3,4]$. However, all clinical trials investigating the addition of novel agents to the R-CHOP backbone as first-line treatment failed to show improvement of OS so far [5].

Vincristine-induced peripheral neuropathy (VIPN), which is commonly a sensorimotor neuropathy, remains a major complication of lymphoma patients treated with R-CHOP. 
VIPN can be observed in $20-40 \%$ of DLBCL patients leading to an increase in morbidity and a decrease in quality of life [6-9]. However, the clinical features and symptoms are variable and range from mild neurologic signs like numbness, which may disappear with discontinuation of vincristine, to severe permanent neurological long-term sequela such as gross and fine motoric deficits, e.g., impaired handwriting $[10,11]$.

The key mechanism of vinca-alkaloid action and induction of neuropathy is inhibition of microtubule polymerization but not all vinca-alkaloids cause the same rate and intensity of chemotherapy-induced neuropathy [12]. Vincristine is the most neurotoxic vinca-alkaloid resulting in peripheral neuropathy of any grade in 18 to $70 \%$ of adult patients [13, 14]. On the contrary, the vinca-alkaloid vinorelbine is rarely associated with peripheral neuropathy occurring in only about $4 \%$ of patients [15].

Dose reduction or discontinuation of vincristine has been commonly used to ameliorate VIPN in R-CHOP-treated DLBCL patients, although this practice is likely associated with impaired treatment outcomes and higher lymphomarelated mortality [16-20]. Nevertheless, there is a lack of studies focusing explicitly on VIPN and the consequences of vincristine dose reductions. In this cohort study, we aimed to delineate the role of vinorelbine as a replacement for vincristine in R-CHOP after onset of peripheral neuropathy in the treatment of de novo DLBCL.

\section{Patients and methods}

\section{Cohort description}

In this retrospective bi-center cohort study, we included 987 patients who were presented for treatment of histologically confirmed de novo DLBCL at the Division of Hematology, Medical University of Graz ("Graz cohort": $n=605$ ), or the third Medical Department at the Paracelsus Medical University Salzburg ("Salzburg cohort": $n=382$ ), both of which are located in Austria, between 2001 and 2020. Patients with human immunodeficiency virus (HIV) positivity, transformed lowgrade lymphoma, high-grade lymphoma, and Burkitt lymphoma, and patients who did not receive full dosage R-CHOP in 21-day cycles (R-CHOP21) were excluded in the Graz cohort for evaluation of vinorelbine treatment (Fig. 1a). Patients treated within the Salzburg cohort met the same inclusion criteria, but dosage of vincristine and doxorubicin was adapted according to adverse events (Supplementary Table 1). Data on baseline characteristics and clinical outcomes were ascertained from our in-house electronic healthcare database system, as previously described $[21,22]$. The research project was approved by the local institutional review boards (EK-Votum: 32-306 ex19/20 ethikkommission@medunigraz.at and EK-Votum: 415-EP/73/ 127-2012 ethikkommission@ salzburg.gv.at).

\section{Rationale behind switching to vinorelbine}

Replacement of vincristine in R-CHOP by vinorelbine has been established as a local standard on an empirical basis in Graz to deliver the full antitumor activity of a vinca-alkaloid after development of any sign of neuropathy. The rationale behind this approach is the substitution of the most neurotoxic vinca-alkaloid vincristine with one of the least neurotoxic, i.e., vinorelbine, in a regimen called Vino-R-CAP in order to reduce or stop progression of VIPN without discontinuation of the substance class.

\section{Treatment and local standard for switching to Vino-R- CAP}

Patients without any signs of neuropathy were treated with R$\mathrm{CHOP}$ and received the combination of $375 \mathrm{mg}$ rituximab per square meter of body-surface area, on day 0 of the treatment cycle; $750 \mathrm{mg}$ of cyclophosphamide per square meter on day 1; $50 \mathrm{mg}$ of doxorubicin per square meter on day $1 ; 1.4 \mathrm{mg}$ of vincristine per square meter, up to a maximal dose of $2 \mathrm{mg}$, on day 1 ; and $100 \mathrm{mg}$ of prednisone per day for 5 days. They were treated every 3 weeks for six to eight cycles of R-CHOP [23]. Patients who developed neutropenia grade $4(<500$ cells $/ \mu \mathrm{L}(0.5$ $\times 10^{9}$ cells/L)) or febrile neutropenia after any cycle of chemotherapy received prophylactically granulocyte colonystimulating factor.

Patients who developed any sign of neuropathy during RCHOP treatment were switched to Vino-R-CAP during the next cycle and received $30 \mathrm{mg}$ of vinorelbine absolute, on day 1 instead of vincristine (Fig. 1a and b).

\section{Assessment of chemotherapy-induced neuropathy}

We assessed VIPN using the National Cancer Institute Common Terminology Criteria for Adverse Events (NCICTCAE) neuropathy sensory subscale version 3 . This outcome measure can be easily accessed by clinicians and used to score patients' symptoms from 0 to 4 (no symptoms to lifethreatening symptoms). However, the measure has also received some criticism due to low interobserver reliability, underestimation of symptoms, and reproducibility of this measure [24-26]. To further improve the reliability of the neuropathy assessment, we included a second, more accurate, and reproducible measurement, the clinical Total Neuropathy Score (cTNS) which is validated for VIPN [27-29]. It comprises seven different parameters of neuropathy (sensory symptoms, motor symptoms, autonomic symptoms, pin sensibility, vibration sensibility, strength, and tendon reflexes) and ranges from 0 to 24 with a higher total score correlating with increasing the severity of the neuropathy [30-32]. 


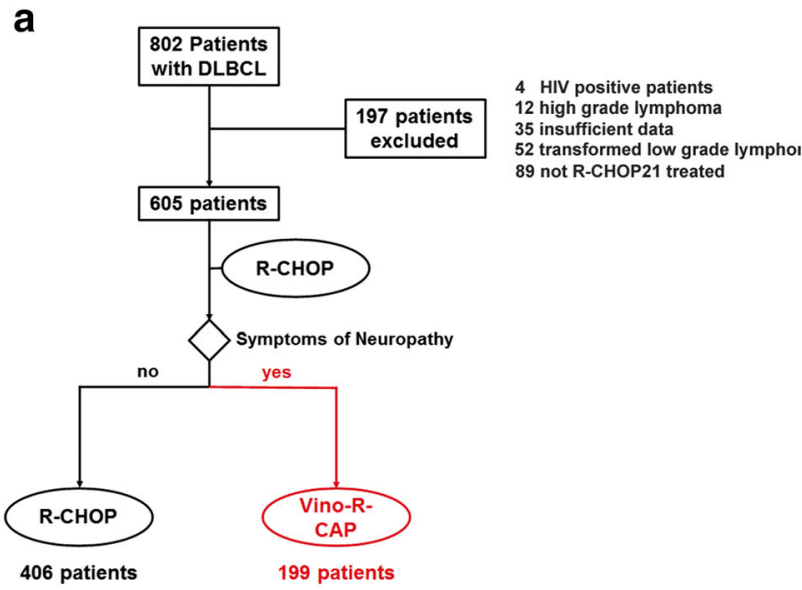

b

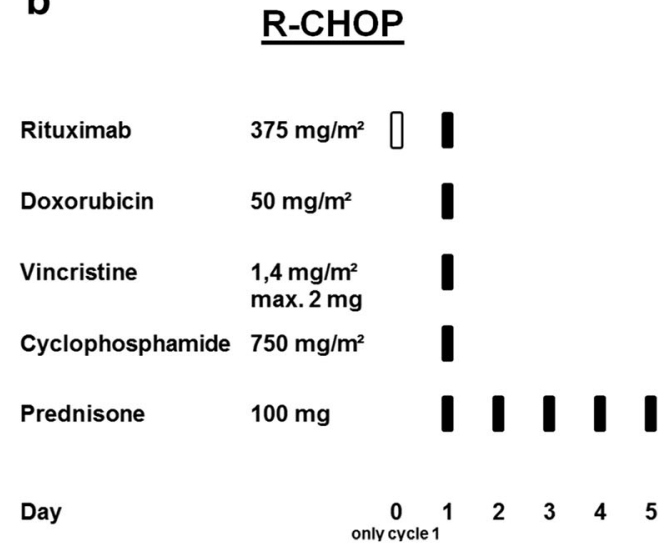

Vino-R-CAP

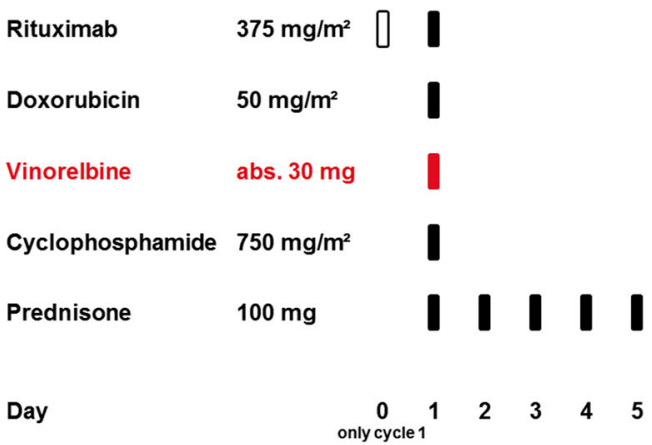

Fig. 1 Full trial protocol of the "Graz cohort" $(n=605)$. a Flow diagram: Comparison of patients which underwent R-CHOP or Vino-R-CAP treatments. b Description of Vino-R-CAP and R-CHOP treatment regimens administered in the cohort. Abbreviations: Vino-R-CAP

\section{Outcomes}

For time-to-event analyses of oncologic outcome, we considered three outcomes: overall survival (OS), progression-free survival (PFS), and DLBCL-specific survival. These outcomes were defined as the time from the date of diagnosis until the occurrence of death-from-any-cause or censoring alive (OS), disease progression or death-from-any-cause or censoring alive, whatever came first (PFS), or death-relatedto-DLBCL or censoring alive or due to death-from-othercauses, whatever came first, respectively. To conduct neuropathy analyses, we considered the continuous change in NCI CTCAE version 3.0 neuropathy grading $[27,30]$, the cTNS grade, and cTNS score [29] from switching to vinorelbine until 2 months thereafter. Moreover, we calculated the proportions of patients who displayed worsening, stable, and improving neuropathy symptoms according to these scores.

\section{Statistical methods}

All statistical analyses were performed with Stata (Windows version 15.1, Stata Corp., Houston, TX, USA). Continuous vinorelbine, rituximab, cyclophosphamide, hydroxydaunorubicin, prednisone; R-CHOP rituximab, cyclophosphamide, hydroxydaunorubicin, vincristine, prednisone

data were reported as medians [25th to 75 th percentile], and the count data were reported as absolute frequencies (\%). Correlations were computed with Spearman's rank-based rho, and associations between variables were investigated with rank-sum tests, $\chi^{2}$ tests, and Fisher's exact tests, simple or multiple linear regression, and paired $t$ tests, as appropriate. The median follow-up was estimated with the reverse KaplanMeier estimator. OS, PFS, and DLBCL-related survival were computed with Kaplan-Meier estimators and compared between two or more groups with log-rank tests. Risks of relapse, death-related-to-DLBCL, and death-from-other-causes were estimated with competing risk cumulative incidence estimators. Modelling of OS, PFS, and DLBCL-related hazard functions was performed with uni- and multivariable Cox regression analyses. A $p$ value of $<0.05$ was considered statistically significant. Importantly, to eliminate immortal time bias, the switch from R-CHOP to Vino-R-CAP was modelled as a so-called time-dependent variable within Cox models. This was achieved by partitioning the follow-up time of patients who were switched to vinorelbine into times before and after the replacement. For visual display of the association between the replacement of vincristine by vinorelbine and oncologic 
outcomes, we performed landmark analyses after the fourth cycle. This landmark date was chosen because most restaging investigations of DLBCL were performed after the fourth immunochemotherapy cycle according to local standards. In subgroup analyses, we fitted interactions between the switch to vinorelbine as time-dependent variables and selected prognostically relevant co-variables of interest. Interaction $p$ values $<0.05$ were considered to indicate statistical significance in these sub-analyses. Missing data are reported in Table 1, and a complete case analysis was performed. The full analysis code is available on request from FP.

\section{Results}

\section{Evaluation of treatment outcomes after reduction of vincristine due to neuropathy}

First, we clarified whether the standard of care (dose reduction or discontinuation of vincristine due to neuropathy) led to impaired outcomes. Therefore, we analyzed 382 DLBCL patients who were treated with RCHOP ("Salzburg cohort"). In these patients, the vincristine dose was reduced to $1 \mathrm{mg}$ or discontinued if neuropathic signs were observed during the treatment course at the discretion of the treating physician (Supplementary Table 1). In this cohort, the 1-, 5-, and 10-year PFS rates were $78.0 \%$ (95\% CI, 74.1$82.6)$, $57.6 \%$ (52.4-62.4), and 46.2\% (28.2-65.5), respectively. The corresponding 1-, 5-, and 10-year OS rates were $87.1 \%(83.6-90.1), 67.3 \%$ (62.3-73.1), and $56.2 \%$ (33.6-78.3), respectively. The Kaplan-Meier analysis results revealed a highly significant association between vincristine dose reduction and poor OS (Fig. 2a) and PFS (Fig. 2b). In detail, 5-year OS and PFS were $72.6 \%$ (95\% CI, 75.9-69.1) and 63.1\% (58.368.0) in patients with full dosage of vincristine during the whole treatment course, and $60.6 \%(64.4-66.5)$ and $51.7 \%(41.1-61.0 \%)$ in patients receiving reduced dose vincristine (log-rank $p=0.022$ and $p=0.028$ for OS and PFS, respectively). To determine the independent prognostic value of vincristine dose reduction, multivariable analyses were carried out including R-IPI, ECOG, and doxorubicin dose reduction (Supplementary Table 2). Here, the prognostic association between vincristine dose reduction and worse OS and PFS prevailed.

\section{Baseline characteristics and treatment outcomes of patients treated with Vino-R-CAP}

Having shown that dose reduction or discontinuation of vincristine results in impaired clinical outcomes, we next investigated the effects of replacing vincristine with vinorelbine because of VIPN. The "Graz cohort" consisted of 605 patients (median age, 65 years; female, $49 \%$; median NCCNIPI, 3 points; Table 1) and approximately half of the cohort had clinical stage III-IV disease, extranodal manifestation, and/or a non-germinal center B cell (GCB) cell of origin tumor. The overall response rate to first-line therapy was $90 \%$ (95\%CI, 87-92). During a median follow-up of 8.5 years, we observed 96 primary disease progressions (16\%), 87 relapses (14\%), 144 deaths from DLBCL (24\%), and 107 deaths from other causes (18\%), respectively. This corresponded to 1-, 3-, 5 -, and 10-year OS estimates of $88 \%, 75 \%, 70 \%$, and $54 \%$, respectively. The corresponding PFS estimates and risks of relapse, death-from-lymphoma, and death-from-other-causes are reported in Supplementary Figure 1 and Supplementary Table 3.

One hundred and ninety-nine patients (33\%) were switched from R-CHOP to Vino-R-CAP after a median of two cycles [25th-75th percentile, 2-4] due to VIPN. Baseline characteristics were similar between both groups (Table 1), except that patients who were switched to Vino-R-CAP received on average 0.45 cycles more therapy $(p=0.005)$ which was related to a slightly lower prevalence of primary progressive disease and thus a higher likelihood of competing first-line therapy $(p=0.009)$. This association between change of therapy and slightly higher number of treatment cycles did not prevail after adjusting for treatment response (Supplementary Table 4).

\section{Neuropathy improves after switching from R-CHOP to Vino-R-CAP}

Next, we determined whether switching from vincristine to vinorelbine could improve neuropathy symptoms as measured by NCI-CTCAE and cTNS.

In the 199 patients who changed over to Vino-R-CAP, neuropathy severity at the time of the switch according to NCI-CTCAE was assessed as grade 1 in 63 patients (32\%), grade 2 in 118 patients (59\%), grade 3 in 17 patients (9\%), and grade 4 in one patient (1\%). This patient with grade 4 neuropathy had to be admitted to the neurologic intensive care unit due to progressive paralysis. Measures of neuropathy severity improved from the time the switch occurred until 2 months after the last treatment cycle. In detail, neuropathy according to NCI-CTCAE improved by 1.1 grades, and neuropathy according to the cTNS grade by 0.6 grades (both $p<0.0001$, Fig. 3a and Supplementary Table 5). Similarly, neuropathy according to NCI-CTCAE and cTNS improved in $79 \%$ and $53 \%$ of patients, respectively, with only $2 \%$ and $6 \%$ of patients displaying worsening neuropathy on the Vino-R-CAP regimen (Fig. 3b). The two neuropathy scoring systems were highly correlated with each other (Spearman's $\rho$ correlating 
Table 1 Baseline characteristics of the study population: distribution by switch status $(n=605)$.

\begin{tabular}{|c|c|c|c|c|c|}
\hline Variable & $N(\%$ miss. $)$ & Overall $(n=605)$ & Vincristine group $(n=406)$ & Vinorelbine group $(n=199)$ & $p$ value* \\
\hline \multicolumn{6}{|l|}{ Demographic variables } \\
\hline Age (years) & $605(0 \%)$ & $65[54-74]$ & $64[52-74]$ & $65[56-73]$ & 0.835 \\
\hline Female gender & $605(0 \%)$ & $299(49 \%)$ & $197(49 \%)$ & $102(51 \%)$ & 0.527 \\
\hline ECOG (points) & $604(0 \%)$ & $1[0-1]$ & $1[0-1]$ & $1[0-1]$ & 0.106 \\
\hline \multicolumn{6}{|l|}{ Tumor characteristics } \\
\hline Cell of origin: Non-GCB & $575(5 \%)$ & $300(52 \%)$ & $212(53 \%)$ & $88(50 \%)$ & 0.488 \\
\hline Clinical stage: III-IV & $605(0 \%)$ & $322(53 \%)$ & $209(51 \%)$ & $113(57 \%)$ & 0.219 \\
\hline Extranodal manifestation & $605(0 \%)$ & $320(53 \%)$ & $216(53 \%)$ & $104(52 \%)$ & 0.828 \\
\hline Double expressor biology** & $405(33 \%)$ & / & / & / & 0.253 \\
\hline 0 points & 1 & $79(20 \%)$ & $59(20 \%)$ & $20(19 \%)$ & / \\
\hline 1 point & / & $231(57 \%)$ & $176(59 \%)$ & $55(52 \%)$ & / \\
\hline 2 points & / & $95(23 \%)$ & $64(21 \%)$ & $31(29 \%)$ & / \\
\hline \multicolumn{6}{|l|}{ Risk stratification } \\
\hline R-IPI (points) & $605(0 \%)$ & $2[2-3]$ & $2[2-3]$ & $3[2-3]$ & 0.491 \\
\hline NCCN-IPI (points) & $605(0 \%)$ & $3[2-5]$ & $3[2-4]$ & $3[2-5]$ & 0.269 \\
\hline CNS-IPI (points) & $605(0 \%)$ & $1[1-2]$ & $1[1-2]$ & $2[1-2]$ & 0.239 \\
\hline \multicolumn{6}{|l|}{ Treatment characteristics } \\
\hline Cycles of primary treatment & $605(0 \%)$ & $6[6-8]$ & $6[6-8]$ & $6[6-8]$ & 0.005 \\
\hline Cycles before switch to vinorelbine & $199(0 \%)$ & l & l & $2[2-4]$ & I \\
\hline ASCT & $605(0 \%)$ & $45(7 \%)$ & $29(7 \%)$ & $16(8 \%)$ & 0.693 \\
\hline \multicolumn{6}{|l|}{ Outcomes } \\
\hline Best response to first-line therapy & $605(0 \%)$ & / & l & l & 0.009 \\
\hline $\mathrm{CR}$ & / & $498(82 \%)$ & $322(79 \%)$ & $176(88 \%)$ & / \\
\hline PR & / & $46(8 \%)$ & $33(8 \%)$ & $13(7 \%)$ & / \\
\hline $\mathrm{PD}$ & / & $61(10 \%)$ & $51(13 \%)$ & $10(5 \%)$ & / \\
\hline Long-term outcomes & $605(0 \%)$ & / & / & / & 0.004 \\
\hline No relapse & 1 & $422(70 \%)$ & $269(66 \%)$ & $153(77 \%)$ & 1 \\
\hline Relapse & / & $87(14 \%)$ & $59(15 \%)$ & $28(14 \%)$ & / \\
\hline Primary progression & / & $96(16 \%)$ & $78(19 \%)$ & $18(9 \%)$ & / \\
\hline Death from DLBCL & $605(0 \%)$ & $144(24 \%)$ & $105(26 \%)$ & $39(20 \%)$ & 0.089 \\
\hline Death from other causes & $605(0 \%)$ & $107(18 \%)$ & $65(16 \%)$ & $42(21 \%)$ & 0.123 \\
\hline
\end{tabular}

$N(\%$ miss.) denotes the number of patients with fully observed variable (\% missing denotes the percentage of patients with lack of data). * $p$ values are from rank-sum tests, $\chi^{2}$ tests, and Fisher's exact tests, as appropriate. **Double expressor biology as assessed by immunohistochemistry for BCL2 and MYC with scoring according to the published algorithm of Hans et al. [33]

Abbreviations: ECOG Eastern Cooperative Oncology Group performance status, GCB germinal center B cell, R-IPI Revised International Prognostic Index, NCCN-IPI National Comprehensive Cancer Network International Prognostic Index, CNS-IPI Central Nervous System International Prognostic Index, $A S C T$ autologous stem cell transplantation, $C R$ complete remission, $P R$ partial remission, $P D$ progressive disease, $D L B C L$ diffuse large $\mathrm{B}$ cell lymphoma

neuropathy scores at switching according to NCI-CTCAE and TNS grade $=0.78, p<0.001$, Fig. $3 c$ ). These results demonstrate a favorable neuropathy outcome after replacing vincristine with vinorelbine.

\section{Switching from R-CHOP to Vino-R-CAP is associated with a higher survival outcome}

To further evaluate outcomes in patients treated with Vino-R-CAP, we performed a univariable time-to-event regression analysis treating substitution of vincristine as a time-dependent variable. Patients who changed over to Vino-R-CAP displayed better outcomes regarding OS, PFS, and DLBCL-related mortality (Supplementary Table 6). These findings prevailed in multivariable regression analyses adjusting for important prognostic covariates, such as NCCN-IPI, double expressor biology, and cell of origin (Supplementary Table 6). In a landmark analysis after the fourth treatment cycle (94 days of follow-up), 5-year OS estimates were $75 \%$ and $70 \%$ 

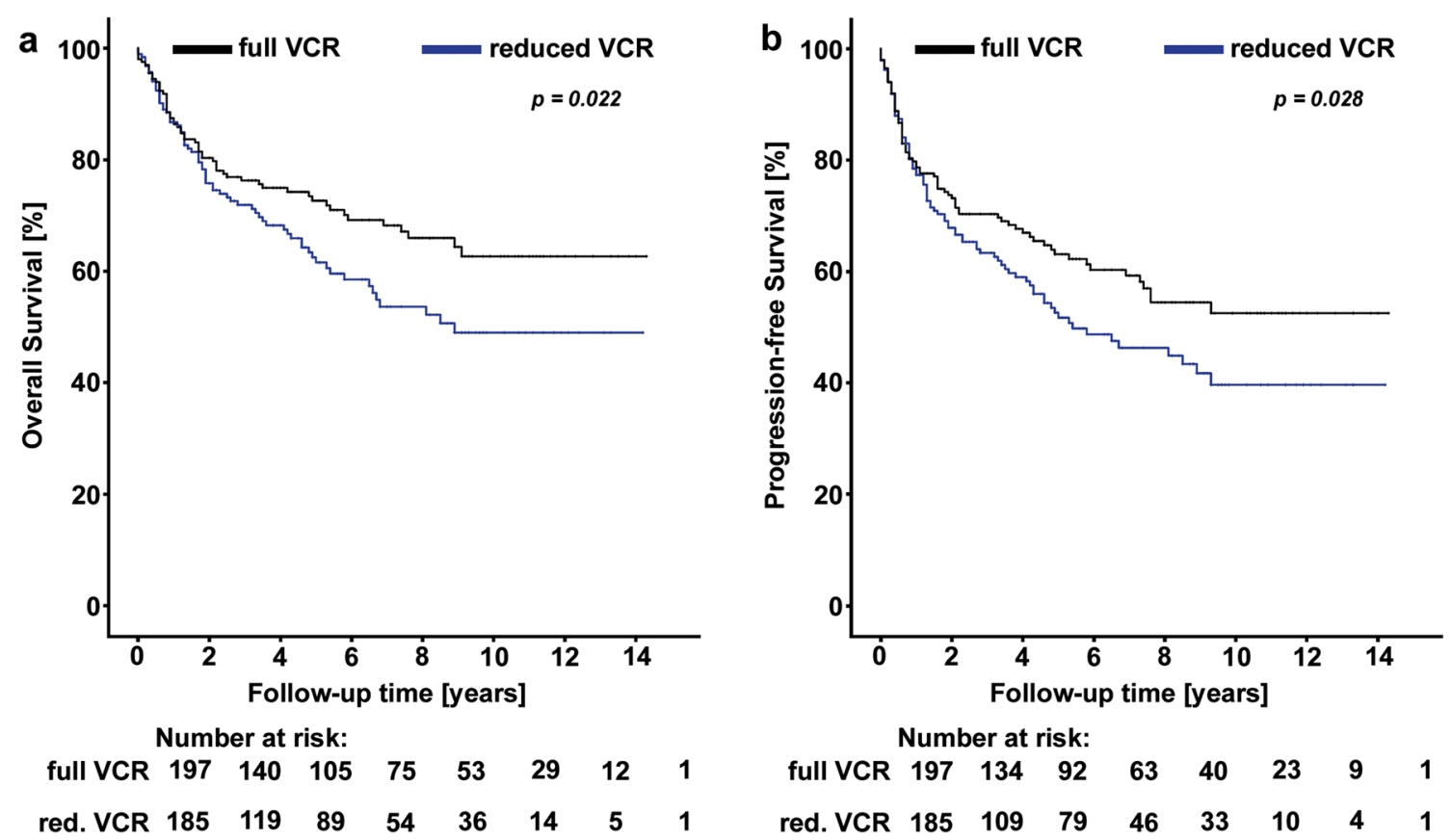

Fig. 2 Survival analyses of oncologic outcome according to vincristine dose reduction in the "Salzburg cohort" $(n=382)$. a Overall survival. b Progression-free survival. Abbreviations: VCR vincristine

in patients that were and were not switched over to vinorelbine (Mantel-Byar $p=0.063$, Fig. 4a). Accordingly, PFS and DLBCL-related survival were significantly in favor of Vino-R-CAP. Compared to RCHOP, 5-year PFS estimates were $73 \%$ versus $62 \%$ (Mantel-Byar $p=0.045$ ), and DLBCL-related survival estimates $84 \%$ versus $78 \%$ (Mantel-Byar $p=0.035$ ), respectively (Fig. 4b, c). Subgroup analyses were performed to determine which patients benefited the most from switching to Vino-R-CAP. Particularly favorable associations between Vino-R-CAP and long-term survival outcome were identified in elderly patients, in patients who crossed over to Vino-R-CAP after the first three cycles of R-CHOP therapy, and in patients with high-risk DLBCL according to NCCN-IPI (Supplementary Table 8, Fig. 5). Overall, the favorable long-term outcome of patients who switched to Vino-RCAP was consistent across all subgroups such as ECOG performance status (interaction $p=0.619$ ), clinical stage (interaction $p=0.709$ ), extranodal disease manifestation (interaction $p=0.131$ ), and double expressor lymphoma biology (interaction $p=0.839$, Fig. 5).

\section{R-CHOP and Vino-R-CAP show similar adverse events}

Adverse events during Vino-R-CAP treatment were consistent with the expected toxic effects of R-CHOP occurring with similar frequencies in both groups (Supplementary Table 7) [6]. The most common adverse event was infection which occurred in $48 \%$ of R-CHOP and $46 \%$ of Vino-R-CAP treated patients. Accordingly, there was no difference in severe chemotherapy-related events like neutropenia, thrombocytopenia, or organ toxicity.

\section{Discussion}

The R-CHOP immunochemotherapy regimen achieves reasonable survival and cure rates in patients with DLBCL [4, 6, 34]. Despite all efforts which have been made in unraveling the molecular mechanisms of lymphomagenesis, establishing new risk models for outcome prediction, and employing promising new substances for treatment within clinical trials, (R)-CHOP continues to represent the standard first-line therapy for the last 40 years [2]. One of the major toxic sequelae caused by this regimen is VIPN which affects between 20 and $40 \%$ of all patients [4, 6-9]. A retrospective analysis from Korea reports VIPN rates of up to $85 \%$ in patients with DLBCL or follicular lymphoma treated with RCHOP causing deterioration in quality of life [35]. Known risk factors of VIPN are cumulative dose of

Fig. 3 Two measures of neuropathy in patients who were switched to vinorelbine $(n=199)$. a Mean neuropathy scores at and after switch to vinorelbine. b Proportion of patients with worsening, stable, and improving neuropathy after switching to vinorelbine. c Correlation between neuropathy grades according to NCI CTC and TNS scores 

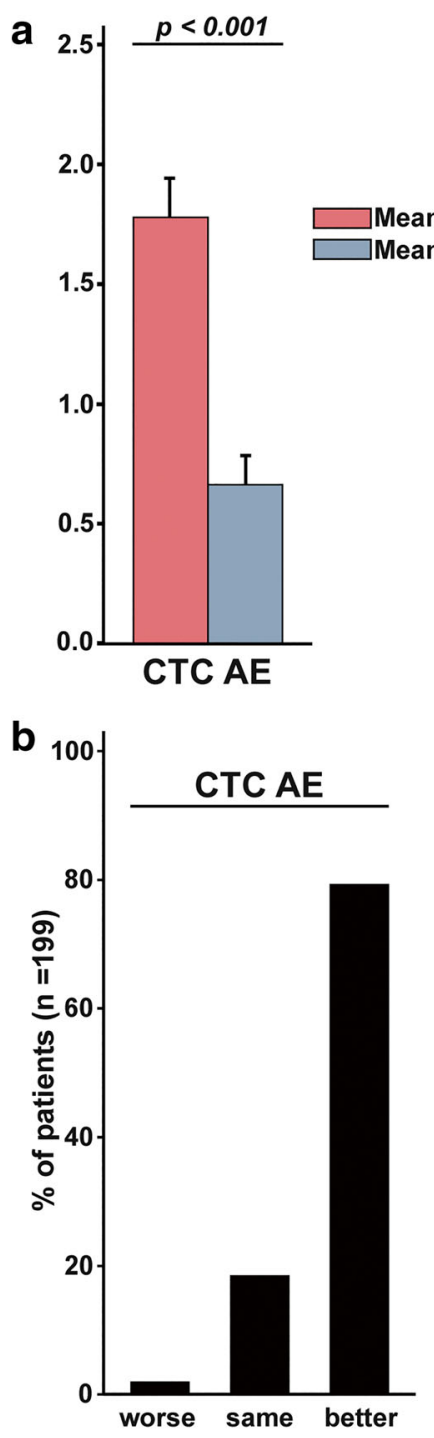
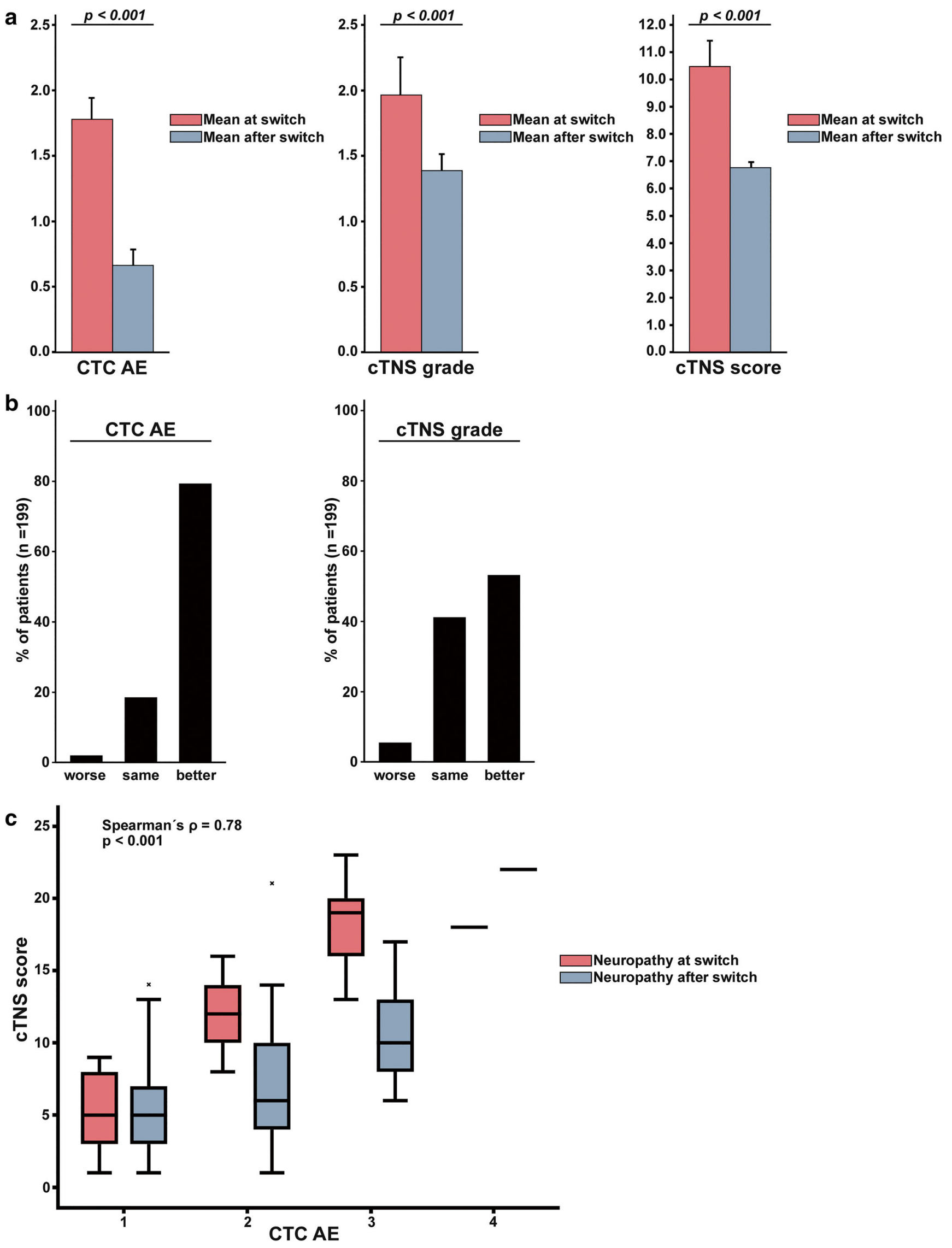

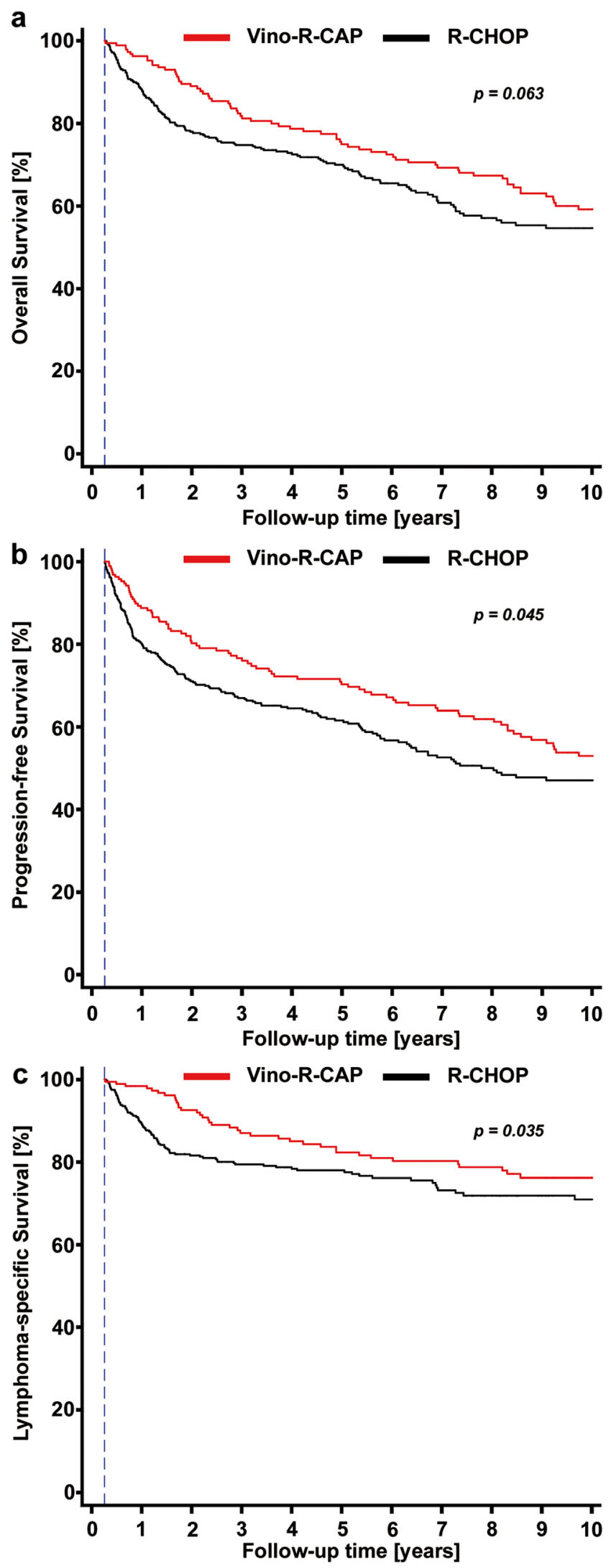

vincristine, older age, and ethnicity, as well as genetic polymorphisms [36-39]. The most common approach to
Fig. 4 Landmark analyses of oncologic outcome according to switch to vinorelbine. The landmark date (blue dashed line) was set at the fourth treatment cycle (approximately 94 days of follow-up). a Overall survival. b Progression-free survival. c DLBCL-specific survival

influence VIPN during R-CHOP treatment is dose reduction or discontinuation of vincristine. However, there is increasing evidence that dose-dense chemotherapy is seminal for improving remission and survival rates [16-20]. To the best of our knowledge, there are only two published studies focusing on the issue of vincristine dose reduction in DLBCL patients delivering contradictory results regarding survival outcomes [19, 40]. Utsu et al. showed significantly impaired outcomes in patients with vincristine dose reduction due to neuropathy which is in agreement with our data provided in the "Salzburg-Cohort." They had very stringent inclusion criteria and considered only de novo DLBCL patients treated with R-CHOP21 similar to our study [19]. On the contrary, there was no difference in treatment outcomes between patients with or without vincristine dose reduction in the study by Mörth et al. However, they had more arbitrary inclusion criteria with a more heterogeneous patient population and different chemotherapy regimens probably leading to a profound selection bias. Nonetheless, both studies did not demonstrate an improvement of VIPN after vincristine dose reduction.

Here, we present a large "real world" cohort of patients with de novo DLBCL treated with R-CHOP in 21-day cycles showing a VIPN rate of $32 \%(199 / 605)$ which is in agreement with published large prospective trials [4, 6-9]. We provide for the first time evidence of a neurologic benefit following substitution instead of dose reduction of vincristine. This benefit was documented by two different neuropathy measures, the easily assessable NCI-CTCAE score and the more accurate and reliable cTNS, which correlated significantly with each other [27-29]. Furthermore, our results suggest an improvement of survival outcomes after switching to Vino-R-CAP. One might speculate that patients who were treated with vinorelbine during first-line treatment received an additional cytostatic substance targeting remaining vincristine-resistant lymphoma cells $[15,41]$. It has been established that vinorelbine is an effective salvage agent in relapsed or refractory aggressive NHL. Blazarotti et al. showed overall response rates of $46 \%$ for vinorelbine as single agent in heavily pre-treated lymphoma patients [42]. Moreover, vinorelbine has been used in different salvage regimens for relapsed or refractory DLBCL as combination partner because it has no-cross resistance properties with other vinca alkaloids $[43,44]$. However, these findings are preliminary and can only be interpreted as hypothesis generating. 
Fig. 5 Subgroup analysis: Forest plot of the relative association of R-CHOP and Vino-R-CAP with 10 -year overall survival according to selected clinical covariables. Black dots represent the subgroup hazard ratio, and the associated bars the $95 \%$ confidence interval. The black vertical line represents the "line of unity," at which patients who were and were not switched to vinorelbine have similar hazards of death-from-any-cause.

Regression results were obtained by fitting an interaction between the vinorelbine switch as a timedependent variable and the respective subgroup variable. Note that the "Low" and "LowIntermediate" categories of the NCCN-IPI had to be merged due to an extremely low number of deaths in the "Low" group that prevented convergence of the HR hazard ratio, OS overall survival, 95\%CI 95\% confidence interval, ECOG Eastern Cooperative Oncology Group, GCB germinal center B cell, DEL double expressor lymphoma, NCCN-IPI National International Prognostic Index regression model. Abbreviations:

Comprehensive Cancer Network

Variable and Subgroup

HR for OS $(95 \% \mathrm{Cl})$

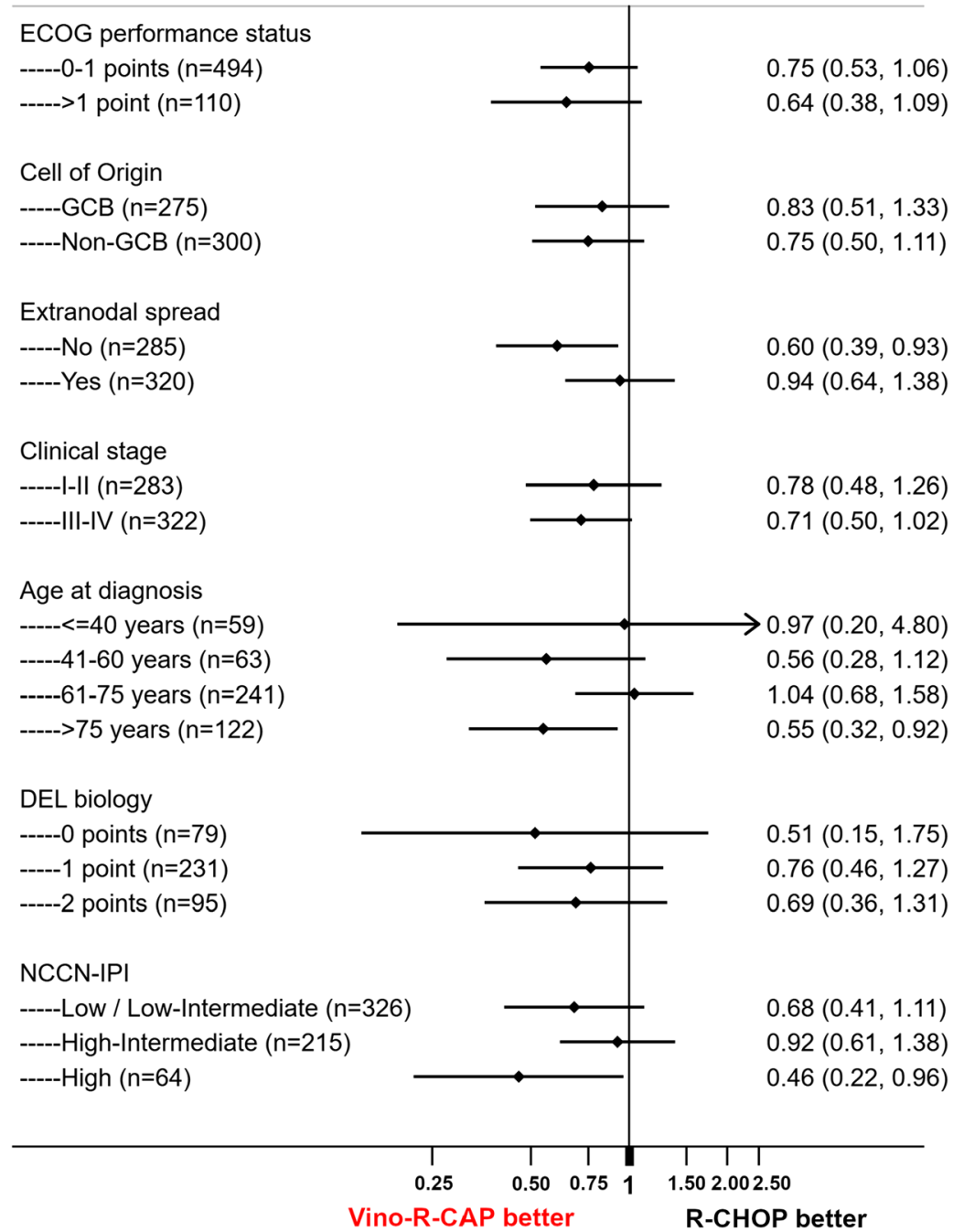

The main limitation of our study is its retrospective nature; however, the patient cohort is characterized by very stringent inclusion criteria and long follow-up providing a 20-year "real world" experience. Although it has to be proven in a randomized controlled trial, based on our robust retrospective data, we can conclude that switching to Vino-R-CAP is safe and more effective than reducing vincristine dose when DLBCL patients develop neuropathy during treatment with R-CHOP.

Supplementary Information The online version contains supplementary material available at https://doi.org/10.1007/s00520-021-06059-2.

Authors' contribution Conception and design: S. Hatzl, F. Posch, P. Neumeister

Development of methodology: S. Hatzl, F. Posch

Acquisition of data (provided animals, acquired and managed patients, provided facilities, etc.): S. Hatzl, A. Rezai, P. Neumeister

Analysis and interpretation of data (e.g., statistical analysis, biostatistics, computational analysis): S. Hatzl, F. Posch, E. Schulz, P. Neumeister
Writing, review, and/or revision of the manuscript: S. Hatzl, F. Posch, A. Rezai, M. Gornicec, C. Beham-Schmid, T. Magnes, S. Wangner, A. Deutsch, H. Greinix, B. Uhl, KT. Prochazka, A. Egle, R. Greil, T. Melchardt, E. Schulz, P. Neumeister

Administrative, technical, or material support (i.e., reporting or organizing data, constructing databases): S. Hatzl, P. Neumeister, F. Posch

Study supervision: S. Hatzl

Funding Open access funding provided by Medical University of Graz.

Data availability The full dataset is available on request from $\mathrm{SH}$.

Code availability The full analysis code is available on request from FP or SH.

\section{Declarations}

Ethical approval All procedures performed in studies involving human participants were in accordance with the ethical standards of the institutional and/or national research committee and with the 1964 Helsinki declaration and its later amendments or comparable ethical standards. 
This article does not contain any studies with human participants or animals performed by any of the authors.

Approval of the local institutional review board: (EK-Votum: 32-306 ex19/20 ethikkommission@medunigraz.at and EK-Votum: 415-EP/73/ 127-2012 ethikkommission@salzburg.gv.at)

\section{Consent to participate N/A}

Consent for publication N/A

Conflict of interest The authors declare no competing interests.

Open Access This article is licensed under a Creative Commons Attribution 4.0 International License, which permits use, sharing, adaptation, distribution and reproduction in any medium or format, as long as you give appropriate credit to the original author(s) and the source, provide a link to the Creative Commons licence, and indicate if changes were made. The images or other third party material in this article are included in the article's Creative Commons licence, unless indicated otherwise in a credit line to the material. If material is not included in the article's Creative Commons licence and your intended use is not permitted by statutory regulation or exceeds the permitted use, you will need to obtain permission directly from the copyright holder. To view a copy of this licence, visit http://creativecommons.org/licenses/by/4.0/.

\section{References}

1. Li S, Young KH, Medeiros LJ (2018) Diffuse large B-cell lymphoma. Pathology. 50:74-87

2. Liu Y, Barta SK (2019) Diffuse large B-cell lymphoma: 2019 update on diagnosis, risk stratification, and treatment. Am J Hematol 94:604-616

3. Sehn LH, Gascoyne RD (2015) Diffuse large B-cell lymphoma: optimizing outcome in the context of clinical and biologic heterogeneity. Blood. 125:22-32

4. Coiffier B, Thieblemont C, Van Den Neste E et al (2010) Longterm outcome of patients in the LNH-98.5 trial, the first randomized study comparing rituximab-CHOP to standard $\mathrm{CHOP}$ chemotherapy in DLBCL patients: a study by the Groupe d'Etudes des Lymphomes de l'Adulte. Blood. 116:2040-2045

5. Mondello P, Mian M (2019) Frontline treatment of diffuse large Bcell lymphoma: beyond R-CHOP. Hematol Oncol 37:333-344

6. Coiffier B, Lepage E, Briere J et al (2002) CHOP chemotherapy plus rituximab compared with $\mathrm{CHOP}$ alone in elderly patients with diffuse large-B-cell lymphoma. N Engl J Med 346:235-242

7. Récher C, Coiffier B, Haioun C, Molina TJ, Fermé C, Casasnovas O, Thiéblemont C, Bosly A, Laurent G, Morschhauser F, Ghesquières H, Jardin F, Bologna S, Fruchart C, Corront B, Gabarre J, Bonnet C, Janvier M, Canioni D, Jais JP, Salles G, Tilly H (2011) Intensified chemotherapy with ACVBP plus rituximab versus standard CHOP plus rituximab for the treatment of diffuse large B-cell lymphoma (LNH03-2B): an open-label randomised phase 3 trial. Lancet. 378:1858-1867

8. Ohmachi K, Tobinai K, Kobayashi Y, Itoh K, Nakata M, Shibata T, Morishima Y, Ogura M, Suzuki T, Ueda R, Aikawa K, Nakamura S, Fukuda H, Shimoyama M, Hotta T, members of the Lymphoma Study Group of the Japan Clinical Oncology Group (JCOG-LSG) (2011) Phase III trial of CHOP-21 versus CHOP-14 for aggressive
non-Hodgkin's lymphoma: final results of the Japan Clinical Oncology Group Study, JCOG 9809. Ann Oncol 22:1382-1391

9. Rummel MJ, Niederle N, Maschmeyer G, Banat GA, von Grünhagen U, Losem C, Kofahl-Krause D, Heil G, Welslau M, Balser C, Kaiser U, Weidmann E, Dürk H, Ballo H, Stauch M, Roller F, Barth J, Hoelzer D, Hinke A, Brugger W (2013) Bendamustine plus rituximab versus CHOP plus rituximab as first-line treatment for patients with indolent and mantle-cell lymphomas: an open-label, multicentre, randomised, phase 3 noninferiority trial. Lancet. 381:1203-1210

10. Staff NP, Grisold A, Grisold W et al (2017) Chemotherapy-induced peripheral neuropathy: a current review. Ann Neurol 81:772-781

11. Li T, Timmins HC, Lazarus HM et al (2020) Peripheral neuropathy in hematologic malignancies - past, present and future. Blood Rev 100653

12. Martino E, Casamassima G, Castiglione S, Cellupica E, Pantalone S, Papagni F, Rui M, Siciliano AM, Collina S (2018) Vinca alkaloids and analogues as anti-cancer agents: looking back, peering ahead. Bioorg Med Chem Lett 28:2816-2826

13. Postma TJ, Benard BA, Huijgens PC, Ossenkoppele GJ, Heimans JJ (1993) Long-term effects of vincristine on the peripheral nervous system. J Neuro-Oncol 15:23-27

14. Verstappen CC, Koeppen S, Heimans JJ et al (2005) Dose-related vincristine-induced peripheral neuropathy with unexpected offtherapy worsening. Neurology. 64:1076-1077

15. Devizzi L, Santoro A, Bonfante V, Viviani S, Bonadonna G (1996) Vinorelbine: a new promising drug in Hodgkin's disease. Leuk Lymphoma 22:409-414

16. Juul MB, Jensen PH, Engberg H, Wehberg S, Dessau-Arp A, Haziri D, Kristensen HB, Baech J, Schurmann L, Clausen MR, Valentin R, Knudsen LM, Munksgaard L, el-Galaly TC, Frederiksen H, Larsen TS (2018) Treatment strategies and outcomes in diffuse large B-cell lymphoma among 1011 patients aged 75 years or older: a Danish population-based cohort study. Eur J Cancer 99:86-96

17. Terada $Y$, Nakamae H, Aimoto R et al (2009) Impact of relative dose intensity (RDI) in CHOP combined with rituximab (R-CHOP) on survival in diffuse large B-cell lymphoma. J Exp Clin Cancer Res 28:116-9966-28-116

18. Hirakawa T, Yamaguchi H, Yokose N, Gomi S, Inokuchi K, Dan K (2010) Importance of maintaining the relative dose intensity of CHOP-like regimens combined with rituximab in patients with diffuse large B-cell lymphoma. Ann Hematol 89:897-904

19. Utsu Y, Takaishi K, Inagaki S, Arai H, Yuasa H, Masuda S, Matsuura Y, Aotsuka N, Wakita H (2016) Influence of dose reduction of vincristine in R-CHOP on outcomes of diffuse large B cell lymphoma. Ann Hematol 95:41-47

20. Wästerlid T, Harrysson S, Andersson TM et al (2020) Outcome and determinants of failure to complete primary R-CHOP treatment for reasons other than non-response among patients with diffuse large B-cell lymphoma. Am J Hematol 95:740-748

21. Hatzl S, Posch F, Schulz E, Gornicec M, Deutsch A, BehamSchmid C, Pichler M, Greinix H, Sill H, Zebisch A, Neumeister P, Prochazka KT (2020) The role of immunohistochemical overexpression of $\mathrm{p} 53$ as adverse prognostic factor in primary testicular diffuse large b cell lymphoma. Pathol Oncol Res 26:2831-2833

22. Hatzl S, Posch F, Deutsch A, Beham-Schmid C, Stöger H, Greinix H, Pichler M, Neumeister P, Prochazka KT (2020) Immunohistochemistry for c-myc and bcl-2 overexpression improves risk stratification in primary central nervous system lymphoma. Hematol Oncol 38:277-283

23. Cunningham D, Hawkes EA, Jack A, Qian W, Smith P, Mouncey P, Pocock C, Ardeshna KM, Radford JA, McMillan A, Davies J, Turner D, Kruger A, Johnson P, Gambell J, Linch D (2013) Rituximab plus cyclophosphamide, doxorubicin, vincristine, and prednisolone in patients with newly diagnosed diffuse large B-cell 
non-Hodgkin lymphoma: a phase 3 comparison of dose intensification with 14-day versus 21-day cycles. Lancet. 381:1817-1826

24. Cavaletti G, Frigeni B, Lanzani F, Mattavelli L, Susani E, Alberti P, Cortinovis D, Bidoli P (2010) Chemotherapy-induced peripheral neurotoxicity assessment: a critical revision of the currently available tools. Eur J Cancer 46:479-494

25. Postma TJ, Heimans JJ, Muller MJ, Ossenkoppele GJ, Vermorken JB, Aaronson NK (1998) Pitfalls in grading severity of chemotherapy-induced peripheral neuropathy. Ann Oncol 9:739744

26. Griffith KA, Merkies IS, Hill EE et al (2010) Measures of chemotherapy-induced peripheral neuropathy: a systematic review of psychometric properties. J Peripher Nerv Syst 15:314-325

27. Cavaletti G, Cornblath DR, Merkies IS et al (2013) The chemotherapy-induced peripheral neuropathy outcome measures standardization study: from consensus to the first validity and reliability findings. Ann Oncol 24:454-462

28. Frigeni B, Piatti M, Lanzani F, Alberti P, Villa P, Zanna C, Ceracchi M, Ildebrando M, Cavaletti G (2011) Chemotherapy-induced peripheral neurotoxicity can be misdiagnosed by the National Cancer Institute Common Toxicity scale. J Peripher Nerv Syst 16:228-236

29. Hughes R (2008) NCI-CTC vs TNS: which tool is better for grading the severity of chemotherapy-induced peripheral neuropathy? Nat Clin Pract Neurol 4:68-69

30. Cavaletti G, Frigeni B, Lanzani F, Piatti M, Rota S, Briani C, Zara G, Plasmati R, Pastorelli F, Caraceni A, Pace A, Manicone M, Lissoni A, Colombo N, Bianchi G, Zanna C, Italian NETox Group (2007) The Total Neuropathy Score as an assessment tool for grading the course of chemotherapy-induced peripheral neurotoxicity: comparison with the National Cancer Institute-Common Toxicity Scale. J Peripher Nerv Syst 12:210-215

31. Velasco R, Bruna J, Briani C, Argyriou AA, Cavaletti G, Alberti P, Frigeni B, Cacciavillani M, Lonardi S, Cortinovis D, Cazzaniga M, Santos C, Kalofonos HP (2014) Early predictors of oxaliplatininduced cumulative neuropathy in colorectal cancer patients. J Neurol Neurosurg Psychiatry 85:392-398

32. Lavoie Smith EM, Li L, Chiang C, Thomas K, Hutchinson RJ, Wells EM, Ho RH, Skiles J, Chakraborty A, Bridges CM, Renbarger J (2015) Patterns and severity of vincristine-induced peripheral neuropathy in children with acute lymphoblastic leukemia. J Peripher Nerv Syst 20:37-46

33. Hans CP, Weisenburger DD, Greiner TC, Gascoyne RD, Delabie J, Ott G, Müller-Hermelink HK, Campo E, Braziel RM, Jaffe ES, Pan Z, Farinha P, Smith LM, Falini B, Banham AH, Rosenwald A, Staudt LM, Connors JM, Armitage JO, Chan WC (2004) Confirmation of the molecular classification of diffuse large Bcell lymphoma by immunohistochemistry using a tissue microarray. Blood. 103:275-282

34. McKelvey EM, Gottlieb JA, Wilson HE, Haut A, Talley RW, Stephens R, Lane M, Gamble JF, Jones SE, Grozea PN, Gutterman J, Coltman C, Moon TE (1976) Hydroxyldaunomycin
(Adriamycin) combination chemotherapy in malignant lymphoma. Cancer. 38:1484-1493

35. Kim BJ, Park HR, Roh HJ, Jeong DS, Kim BS, Park KW, Cho SC, So YT, Oh SY, Kim SJ (2010) Chemotherapy-related polyneuropathy may deteriorate quality of life in patients with Bcell lymphoma. Qual Life Res 19:1097-1103

36. Sawaki A, Miyazaki K, Yamaguchi M, Takeuchi T, Kobayashi K, Imai H, Tawara I, Ono R, Nosaka T, Katayama N (2020) Genetic polymorphisms and vincristine-induced peripheral neuropathy in patients treated with rituximab, cyclophosphamide, doxorubicin, vincristine, and prednisone therapy. Int J Hematol 111:686-691

37. Legha SS (1986) Vincristine neurotoxicity. Pathophysiology and management. Med Toxicol 1:421-427

38. Renbarger JL, McCammack KC, Rouse CE, Hall SD (2008) Effect of race on vincristine-associated neurotoxicity in pediatric acute lymphoblastic leukemia patients. Pediatr Blood Cancer 50:769-771

39. Okada N, Hanafusa T, Sakurada T et al (2014) Risk factors for early-onset peripheral neuropathy caused by vincristine in patients with a first administration of R-CHOP or R-CHOP-like chemotherapy. J Clin Med Res 6:252-260

40. Mörth C, Valachis A, Sabaa AA, Molin D, Flogegård M, Enblad G (2018) Does the omission of vincristine in patients with diffuse large B cell lymphoma affect treatment outcome? Ann Hematol 97:2129-2135

41. Devizzi L, Santoro A, Bonfante V, Viviani S, Balzarini L, Valagussa P, Bonadonna G (1994) Vinorelbine: an active drug for the management of patients with heavily pretreated Hodgkin's disease. Ann Oncol 5:817-820

42. Balzarotti M, Santoro A, Tondini C, Fornier M, Bonadonna G (1996) Activity of single agent vinorelbine in pretreated nonHodgkin's lymphoma. Ann Oncol 7:970-972

43. Gyan E, Damotte D, Courby S, Sénécal D, Quittet P, SchmidtTanguy A, Banos A, le Gouill S, Lamy T, Fontan J, Maisonneuve $\mathrm{H}$, Alexis M, Dreyfus F, Tournilhac O, Laribi K, Solal-Céligny P, Arakelyan N, Cartron G, Gressin R, the GOELAMS Group (2013) High response rate and acceptable toxicity of a combination of rituximab, vinorelbine, ifosfamide, mitoxantrone and prednisone for the treatment of diffuse large B-cell lymphoma in first relapse: results of the R-NIMP GOELAMS study. Br J Haematol 162:240 249

44. Papageorgiou ES, Tsirigotis P, Dimopoulos M, Pavlidis N, Fountzilas G, Papageorgiou S, Economopoulos T (2005) Combination chemotherapy with gemcitabine and vinorelbine in the treatment of relapsed or refractory diffuse large B-cell lymphoma: a phase-II trial by the Hellenic Cooperative Oncology Group. Eur J Haematol 75:124-129

Publisher's note Springer Nature remains neutral with regard to jurisdictional claims in published maps and institutional affiliations. 